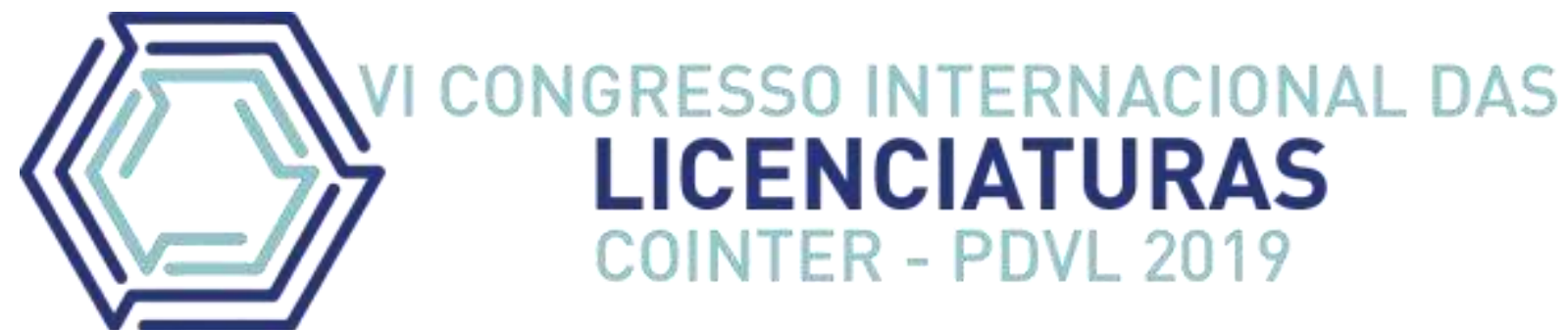

\title{
DROGAS, TEMÁTICA PARA O ENSINO DE CIÊNCIAS NA UNIDADE ESCOLAR MUNICIPAL DESEMBARGADOR SARNEY DE ARAÚJO COSTA: ESTUDO DE CASO
}

\author{
DROGAS, TEMÁTICAS PARA LA ENSEÑANZA DE CIENCIAS EN LA UNIDAD \\ ESCOLAR MUNICIPAL DISEÑADORA SARNEY DE ARAÚJO COSTA: ESTUDIO \\ DE CASO
}

\section{DRUGS, THEMATIC FOR SCIENCE TEACHING IN THE MUNICIPAL SCHOOL UNIT DESIGNER SARNEY DE ARAÚJO COSTA: CASE STUDY}

\author{
Apresentação: Comunicação Oral
}
Magda Daniele Rocha dos Santos ${ }^{1}$; Mariano Oscar Aníbal Ibanez Rojas ${ }^{2}$; Hátila Jossana Muniz Rei ${ }^{3}$ Francisca Inalda Oliveira Santos ${ }^{4}$; Pedro Alberto Pavão Pessôa ${ }^{5}$

\section{DOI: https://doi.org/10.31692/2358-9728.VICOINTERPDVL.2019.0163}

\begin{abstract}
Resumo
A prevenção ao uso de drogas é uma formidável ação que pode ocorrer junto ao ensino de ciências no ensino fundamental. Os alunos, estão sujeitos a um possível início ao consumo de drogas pela disponibilidade embora ilegal, o fácil acesso e principalmente o desejo de inserção a um grupo e por estarem expostos a um grande número de usuários, assim, acredita-se que ações preventivas podem ser mais eficazes do que o tratamento de viciados. Desta forma, o presente trabalho teve como objetivo efetuar uma abordagem sobre drogas e suas consequências como ferramentas de esclarecimento preventivo educativo no $9^{\circ}$ ano da Unidade Escolar Municipal Desembargador Sarney de Araújo Costa, instituição de ensino localizada num bairro periurbano da cidade de Codó-MA. A pesquisa foi realizada com alunos que cursam a disciplina de Ciências. A pesquisa tem natureza qualitativa, para a realização da abordagem foram utilizadas ferramentas de coleta de dados a partir de aplicação de questionários de sondagem previamente elaborados com base na literatura existente e a realidade local. Os questionários foram aplicados aos 25 alunos de ambos os sexos com idade variando entre 14 e 15 anos. A análise dos resultados obtidos permitiu identificar que os alunos, tiveram contato com drogas, tanto lícitas como ilícitas, o tipo de contato, se alguém da família usa ou usou, quais as consequências do uso, quais as drogas conhecidas por eles. Conclui - se que a prevenção ao uso de drogas necessita ser mais debatida nas escolas, com a participação de pais e especialistas,
\end{abstract}

\footnotetext{
1 Especialização em Educação e Ensino de Ciências, IFMA/Caxias GARSA-IFMA, E-mail: magdadanielerds@gmail.com

${ }^{2}$ Professor Doutor, em Química Analítica, IFMA/CODÓ GARSA-IFMA, E-mail: ibanez@ifma.edu.br

${ }^{3}$ Especialização em Educação e Ensino de Ciências, IFMA/Caxias, E-mail: hatila1@ hotmail.com

${ }^{4}$ Professora Mestra, em Sustentabilidade de Ecossistemas IFMA/CODÓ, E-mail: inaldageo@ifma.edu.br

${ }^{5}$ Doutorado em Engenharia e Ciência de Alimentos, IFMA/CODÓ, E-mail pedro.pessoa@ifma.edu.br
} 
numa abordagem contextualizada e interdisciplinar, com base na vivência e conhecimento prévio dos alunos.

Palavras-Chave: Drogas; ensino de ciências; alunos.

\title{
Resumen
}

La prevención de drogas es una acción formidable que puede ocurrir junto con la educación científica en la escuela primaria. Los estudiantes están sujetos a un posible inicio del consumo de drogas debido a la disponibilidad, aunque sea ilegal, de fácil acceso y especialmente el deseo de unirse a un grupo y porque están expuestos a una gran cantidad de usuarios, por lo tanto, se cree que las acciones preventivas pueden ser más eficaz que tratar a los adictos. Así, el presente trabajo tuvo como objetivo hacer un enfoque sobre las drogas y sus consecuencias como herramientas de clarificación educativa preventiva en el noveno grado de la Unidad de la Escuela Municipal Juez Sarney de Araújo Costa, una institución educativa ubicada en un barrio periurbano de la ciudad de Codó- MA. La investigación se realizó con estudiantes que asisten a la disciplina de ciencias. La investigación tiene una naturaleza cualitativa, para realizar el enfoque utilizamos herramientas de recopilación de datos a partir de la aplicación de cuestionarios de encuestas previamente preparados en base a la literatura existente y la realidad local. Los cuestionarios se aplicaron a 25 estudiantes de ambos sexos con edades comprendidas entre 14 y 15 años. El análisis de los resultados obtenidos nos permitió identificar que los estudiantes tuvieron contacto con drogas lícitas e ilícitas, el tipo de contacto, si alguien en la familia usa o usa, cuáles son las consecuencias del uso, qué drogas conocen. Se concluye que la prevención del uso de drogas debe ser más debatida en las escuelas, con la participación de padres y especialistas, en un enfoque contextualizado e interdisciplinario, basado en la experiencia y el conocimiento previo de los estudiantes.

Palabras Clave: Drogas; enseñanza de ciencias; estudiantes.

\begin{abstract}
Drug prevention is a formidable action that can occur alongside science education in elementary school. Students are subject to a possible start to drug use due to availability, although illegal, easy access and especially the desire to join a group and because they are exposed to a large number of users, thus, it is believed that preventive actions can be more effective than treating addicts. Thus, the present work aimed to make an approach on drugs and their consequences as tools of educational preventive clarification in the 9th grade of the Municipal School Unit Judge Sarney de Araújo Costa, an educational institution located in a periurban neighborhood of the city of Codó-MA. The research was conducted with students who attend the science discipline. The research has a qualitative nature, to perform the approach we used data collection tools from the application of survey questionnaires previously prepared based on existing literature and local reality. The questionnaires were applied to 25 students of both sexes with ages ranging from 14 to 15 years. The analysis of the results obtained allowed us to identify that the students had contact with both licit and illicit drugs, the type of contact, if anyone in the family uses or used, what the consequences of the use, which drugs they know. It is concluded that drug use prevention needs to be more debated in schools, with the participation of parents and specialists, in a contextualized and interdisciplinary approach, based on the students' previous experience and knowledge.
\end{abstract}

Keywords: Drugs; science teaching; students. 


\section{Introdução}

Atualmente vemos em revistas, jornais, e em outras fontes de informação que apontam a evolução contínua do uso de drogas que notadamente vem crescendo cada vez mais. Muitos adolescentes estão sujeitos à exposição de drogas no decorrer do seu dia a dia sendo assim eles ficam vulneráveis ao consumo.

Para alguns adolescentes, o uso indevido de substâncias será apenas parte de seu processo de desenvolvimento, podendo cessar com seu amadurecimento. Outros, porém, desenvolverão um uso problemático, interrompendo o processo normal da adolescência, podendo trazer graves consequências para a vida desses indivíduos (SCIVOLETTO, 2001).

São inúmeros os prejuízos acarretados pelo uso de drogas, principalmente aquelas cujos efeitos fisiológicos provocam transtornos psíquicos resultando em agravos materiais independentemente do tipo e quantidade de droga consumida. Além dos prejuízos provocados no vaso físico do usuário, que são refletidos claramente na saúde física com sequelas psíquicas para ele e os responsáveis, provocam transtornos orçamentários nos recursos de gestão da sociedade em que está inserido.

O uso, o abuso e a dependência de drogas constitui-se hoje como um grave problema social e frequentemente inserido no cotidiano das pessoas, seja pelos medicamentos, pelas drogas lícitas (tais como cigarro e bebidas) como também pelas drogas ilícitas (como a cocaína, a maconha e o crack). Seu uso é um ato antigo e muito disseminado principalmente entre os jovens, o que ocasiona graves problemas para o usuário e a sociedade em geral (SILVA et al, 2012).

O termo drogas é bem extenso sendo que a sociedade especifica apenas as drogas licitas e ilícitas, sendo que drogas são qualquer substância química que vem alterando no comportamento dos adolescentes em relação à família, a escola e a sociedade em que vive.

É importante enfatizar que o ambiente escolar faz parte da formação do indivíduo, são nestes lugares que são discutidos assuntos relacionados a drogas juntamente com suas consequências na vida do ser humano. Os adolescentes querem ter sua própria independência, obtendo assim o direito de liberdade, o direito de interagir entre grupos e acabam passando por uma transição de comportamento, na maioria das vezes um comportamento negativo por conta 
do uso excessivo de drogas que trazem consequências comportamentais, físicas e até mesmo emocionais.

É possível evidenciar que o uso de drogas é um dos fatores que vem corrompendo a vida dos jovens, causando retrocesso nas instituições de ensino, sendo que a evasão escolar é um dos fatos mais relevantes nos últimos anos, e o número de alunos desistentes vem aumentando gradativamente nas escolas públicas, principalmente em escolas periféricas, onde a maioria da população vive em situações de catástrofe, condições desesperadoras sendo que para muitos as drogas é a solução dos problemas.

A escola por muitas das vezes é um refúgio para alguns, pois é neste ambiente de ensino que se encontra muitos usuários, muitos buscam mudanças, que se dão através da compreensão, da busca de informações, argumentos, debates de assuntos para que o indivíduo possa buscar meios de prevenção contra o vício.

É na escola que os estudantes são informados sobre o uso excessivo de drogas, sobre as consequências que podem ser causadas, pois muitos não dão importâncias para essas informações, muitas das vezes por acharem que não são obrigados e por outro lado, muitos compreendem que as drogas trazem possíveis mudanças na vida do indivíduo principalmente na sociedade em que vivem.

O presente estudo teve como objetivo efetuar uma abordagem sobre drogas e suas consequências como ferramentas de esclarecimento preventivo educativo no $9^{\circ}$ ano da escola U. E. M. Desembargador Sarney de Araújo Costa, num bairro periurbano da cidade de CodóMA.

A pesquisa permitiu confirmar que todos os alunos conhecem ou tiveram algum tipo de contato com drogas; todos eles entendem que o trabalho da escola na prevenção de drogas é realizar projetos, palestras que possibilitem aos alunos a participarem e ao mesmo tempo ter meios que sirvam de alerta para orientar os alunos a conversar com os pais e não deixarem ser corrompidos por más influências existentes na sociedade.

\section{Fundamentação Teórica}

O segundo Levantamento Domiciliar sobre o Uso de Drogas Psicotrópicas no Brasil constatou, por exemplo, que o consumo de álcool ocorre em faixas etárias cada vez mais precoces, sugerindo a necessidade de revisão das medidas de controle, prevenção e tratamento 
(CEBRID, 2005). É necessária a abordagem dessa temática cada vez mais cedo pela escola visando à prevenção ao uso indevido de drogas.

Na pré-adolescência e adolescência, a idade do início do uso de drogas e seu padrão de consumo são fatores importantes na prevalência elevada do consumo dessas substâncias (VIEIRA et al., 2007). Nessa fase, o indivíduo é particularmente vulnerável do ponto de vista psicológico e social (SOLDERA et al., 2004). Essa é uma fase de procura e de conflitos, na qual os adolescentes dão muita importância aos seus grupos, seus relacionamentos, e entram em conflito consigo mesmos e com a família; isso os torna mais vulneráveis a situações externas, tais como o consumo de drogas, delinquência e condutas de risco (PASUCH; DA SILVA OLIVEIRA, 2014).

Segundo Pechansky, Szobot et al (2004), em um estudo que envolveu 107 grandes cidades brasileiras, cerca de 50\% dos jovens entre 12 e 17 anos já consumiram drogas, sendo que, nesta porcentagem, $5,2 \%$ é dependente de álcool.

As drogas lícitas e ilícitas estão presentes cada vez mais em nosso meio, independente de classe social e, estas têm uma ocorrência espaço temporal farta e são de fácil acesso. Visto que muitos estudantes estão deixando a escola para o consumo das drogas, a que os torna viciados levando-os, em inúmeros casos, à criminalidade ou, quando percebido pelos responsáveis, a serem internados em instituições (CFP, 2013).

O Ensino de Ciências relacionado para as questões das drogas no ambiente escolar pode levar informações aos alunos, dados que podem contribuir para uma tomada de decisão mais racional no que diz respeito às drogas. Na perspectiva da prevenção de diminuir o consumo de tais substâncias lícitas e ilícitas por estudantes e jovens na comunidade escolar (ARALDI et al., 2012).

De acordo com os Parâmetros Curriculares Nacionais (PCN):

O ensino de Ciências, recente na escola fundamental, requer novas teorias de ensino praticado de acordo com diferentes propostas educacionais, respeitando as diversidades regionais, locais, culturais, políticas, existentes no país (BRASIL, 1998).

Com essas propostas que o PCN propõe que é possível que os jovens possam ter mais acesso a todo tipo de conhecimento e informações no decorrer da sua fase escolar para que assim possa exercer o seu exercício de cidadania (MELLO, 2011; MELLO et al., 2012). 
Por meio dos conteúdos estudados seja eles, sociais, culturais e científicos, de certo modo será interessante para os alunos compreender com mais clareza o que se passa ao seu redor, desde a relação entre o ser humano e a natureza, tendo com isso uma melhor interpretação sobre sua realidade, possibilitando ao aluno uma melhor aprendizagem, para que ele possa progredir a cada dia com novos conhecimentos (BRASIL, 1998).

Deste modo, a temática das drogas é um dos temas que, segundo o PCN, é necessário enfocá-lo de maneira diferenciada. Assim, as dificuldades em lidar com o assunto levam a colocar a esperança nos educadores e muita expectativa nas instituições (BRASIL, 2001).

O termo droga possui várias acepções, podendo ser referido a medicamentos ou remédios com propriedades terapêuticas estabelecidas e mais especificamente a substâncias que são capazes de causar dependência e/ou são objeto de abuso. Em um contexto legal o termo "droga" refere-se às substâncias psicoativas e, em particular, às drogas ilícitas ou aquelas cujo uso é regulado por lei. No Brasil, a legislação define como droga "as substâncias ou produtos capazes de causar dependência" assim especificado no parágrafo único art. $1^{\circ}$ da Lei $n^{\circ}$ 11.343/2006 que institui o Sistema Nacional de Políticas Sobre Drogas - SISNAD (LIMA, 2013).

Para a Organização Mundial da Saúde (OMS), “[...] droga é qualquer substância natural ou sintética que, administrada por qualquer via no organismo, afeta sua estrutura ou função [...]", e a pessoa com menor possibilidade de usar a droga é aquela que é bem informada, bem integrada na família e sociedade, com boa saúde e qualidade de vida satisfatória e com difícil acesso às drogas (SANCEVERINO; ABREU, 2004).

Mas de qual drogas estamos falando? Segundo o PCN:

O que chamamos habitualmente de "drogas" corresponde às drogas psicoativas que tem atração por atuar no cérebro, modificando a sensibilidade, o modo de pensar e, muitas vezes, de agir. Isso inclui, além de produtos ilegais como a maconha, crack, cocaína, a nicotina, o álcool e cafeína (BRASIL, 2001).

Quando se fala em droga, ela tem vários tipos diferentes, onde não são todas iguais. Sejam elas lícitas ou ilícitas cada uma vai ter a sua reação, e seus efeitos e os seus males causados devido a dependência do seu uso indiscriminado (BRASIL, 2001).

A Classificação de Transtornos Mentais e de Comportamento (OMS, 1993) tem atualmente a definição do conceito de drogas sendo a mais corrente no meio científico tomada 
desde uma perspectiva biológica "droga é toda substância natural ou sintética que introduzida no organismo vivo, pode modificar uma ou mais de suas funções".

Esta definição esclarece que em um sentido amplo, droga é qualquer substância química, natural ou sintética, capaz de modificar um sistema biológico - daí o termo drogaria nomear o lugar onde são comercializados os medicamentos (LIMA, 2013).

Noto e Galduróz (1999) destacam três níveis de prevenção ao consumo de drogas. A prevenção primária consiste em ações que evitem o primeiro uso de uma determinada substância e a ocorrência de novos casos (OMS, 1992), dando-se, principalmente, por meio da disseminação de informações pelas comunidades. A prevenção secundária consiste em ações para evitar complicações em usuários esporádicos e que ainda não apresentam um nível alto de problemas (OMS, 1992). Já a prevenção terciária desenvolve-se no sentindo de reintegrar o usuário na sua comunidade, melhorando sua qualidade de vida (OMS, 1992), com abordagem sobre o tratamento do vício e auxílio durante as crises de abstinência, além de abordagem psicanalítica e medicamentosa.

A prevenção do uso indevido de drogas é uma tarefa que faz parte da função educacional da escola, fazendo parte do seu projeto pedagógico, inserindo como tema no seu currículo, sendo compartilhada pelos educadores para uma reflexão e construção de responsabilidade social por parte dos alunos (CARDOSO, et al., 2015).

\section{Metodologia}

\section{Localização da Área de Estudo:}

O município de Codó faz parte da Mesorregião Leste Maranhense e integra a microrregião Codó. Está situado na área de transição entre as Regiões dos Cocais e do Cerrado Maranhenses, limitando-se com vários municípios da região: ao norte Timbiras, ao sul Governador Archer, ao leste Caxias, ao Oeste Capinzal do Norte (SANTOS, 2013).

O bairro Nova Jerusalém é um bairro periférico e o mais carente do município de CodóMA. Neste bairro encontra-se a escola Unidade Escolar Municipal Desembargador Sarney de Araújo Costa inaugurada em 16 de abril de 1996, com o nome U. E. M. Dep. José Sarney Filho, tendo mudado de nome no ano 2016 passando a ser chamada U. E. M. Desembargador Sarney de Araújo Costa localizada na praça: Padre Giusep Pelegrini S/N Bairro Nova Jerusalém, CEP: 65400-000; é uma escola com o sistema de ensino público municipal de Codó. 
A escola trabalha com as seguintes modalidades de ensino: ensino fundamental no turno matutino do $2^{\circ}$ ao $6^{\circ}$ ano e no turno vespertino do $6^{\circ}$ ao $9^{\circ}$ ano, no noturno trabalha com o EJA de $2^{\circ}$ a $9^{\circ}$ ano. No entanto os discentes da escola são divididos em aproximadamente 213 alunos no turno matutino, com 280 alunos no turno vespertino e 80 no noturno.

\section{Tipos de estudo: Abordagem Qualitativa}

Para realização do presente estudo foi utilizada uma abordagem qualitativa com os alunos do $9^{\circ}$ ano vespertino da escola Sarney de Araújo Costa, visando alertar os adolescentes sobre o uso de drogas através de questionários estruturados com perguntas abertas e palestras.

A pesquisa foi realizada com alunos que cursam a disciplina de Ciências, sendo que muitos deles possuem censo crítico sobre o assunto abordado.

As turmas são constituídas por 25 alunos de ambos os sexos com idade variando entre 14 e 15 anos, sendo que a maioria dos alunos moram no próprio bairro.

Para iniciar a pesquisa houve a autorização da Gestão da escola e da professora de sala para que fosse realizada a coleta de dados e a participação dos alunos respondendo o questionário.

Utilizamos instrumentos estruturados (questionários). No qual, aplicamos a esta metodologia teórica como Boente e Braga (2004) e Diehl, (2004) que usaram a aplicação de questionários e o crivo de uma análise ampla por parte dos autores a fim de compreender e classificar os problemas e contribuir para o processo de mudança.

O questionário teve como finalidade conhecer a realidade de vida dos adolescentes que tiveram, que tem envolvimento com drogas, e aqueles que em nenhum caso tiberam envolvimento com drogas, com a finalidade de identificar o nível de conhecimento sobre o conceito de drogas. Para esta finalidade foi solicitado aos alunos para que estes não se identificassem, sugerindo-se, no momento da aplicação que estes utilizassem nomes fictícios para assim poderem descrever os relatos a serem efetuados por eles.

\section{Passos metodológicos}

Passo I: Questionário Prévio Aplicar um questionário de conhecimentos prévios com vinte questões de múltipla escolha. 
Passo II: Aula teórica em sala de aula (30 minutos), constituída por apresentação de slides sobre drogas lícitas e ilícitas, compreensão de como entram nas escolas e o que tais produtos fazem com o organismo das pessoas que consomem, com discussões sobre o tema, visando facilitar o processo de aprendizagem sobre conceitos científicos e fortalecimento de atitudes antidrogas e apresentação de um vídeo para fortalecimento dos slides.

\title{
Resultados e Discussão
}

Sobre os 25 questionários, 52\% foram respondidos por alunos do sexo feminino, $61,5 \%$ se identificaram e 38\% não se identificaram. Em relação aos alunos do sexo masculino, 33,3\% se identificaram e $66,6 \%$ não se identificaram totalizando $48 \%$ alunos do sexo masculino.

Dentre os questionários do sexo feminino e masculino com identificação, observou-se que muitos dos adolescentes demonstraram domínio sobre o conceito de drogas e suas consequências.

Neste sentido Bucher (2002) menciona que:

\begin{abstract}
Ao percorrermos a história da civilização, encontramos a presença de drogas, desde os primórdios da humanidade, inseridas nos mais diversos contextos: social, econômico, medicinal, religioso, ritual, cultural, psicológico, estético, climatológico e mesmo militar. O consumo de drogas deve, portanto, ser considerado como um fenômeno, especificamente humano, isto é, um fenômeno cultural: não há sociedade que não tenha as suas drogas, recorrendo a seu uso para finalidades diferentes, em conformidade com o campo de atividade no qual se insere. Alguns autores opinam mesmo que a história do homem é aquela das drogas que consome (BUCHER 2002, p. 8).
\end{abstract}

De acordo com o conceito de drogas apenas 15,3\% das alunas obtiveram uma justificativa concreta, afirmando que as drogas são entorpecentes que a pessoa ao fumar, fica viciado e não sabe o que está acontecendo ao seu redor.

Neste sentido, duas alunas identificadas pelo nome fictício de: Francisca e Antônia, afirmaram que: "droga é um tipo de substância química que os adolescentes usam e pensam que não é prejudicial para saúde”. Conforme a fala de outros alunos, droga é uma substância lícita muito usada por adolescentes, pois é um vício que gera conflito na família e a leva a pessoa a morte.

Muitos dos alunos que não se identificaram não souberam justificar o conceito de drogas, responderam apenas que é algo ruim. Na fala de alguns alunos o uso de drogas é normal, muitos conhecem pessoas da família que são envolvidas com drogas. 
É importante enfatizar que $24 \%$ dos alunos responderam que o próprio pai usa drogas e $16 \%$ responderam que tios, familiares e amigos são envolvidos com drogas. Os resultados apontaram que dentre o total das respostas, $40 \%$ dos alunos responderam que já usaram drogas dentre elas apenas o álcool.

Para completar este estudo Martins (2008) alude que:

O impacto da doença do alcoolismo não incide somente no contexto social mais amplo e na saúde do dependente, uma vez que, a dependência do álcool interfere também na relação familiar, pois os componentes da família vivenciam diariamente a realidade do familiar que enfrenta a dependência do álcool. É importante, portanto, ter clareza de como esse fenômeno se manifesta na relação familiar (MARTINS 2008, p. 25).

Diante deste respaldo é importante enfatizar que, o motivo que levou muitos a usar álcool pela primeira vez foi a curiosidade com idades entre quatorze e quinze anos, dentre esses alunos apensas $8 \%$ responderam que nunca usaram álcool.

Seguindo esta direção Rozin; Zagonel, (2012) Malta et al., (2011) afirmam que no Brasil o álcool é uma substância química que vem afetando adolescentes com faixa etária de 14 e 16 anos, por ser uma das drogas mais consumida pelos jovens, dados da pesquisa nacional de saúde escolar afirma que $70 \%$ dos jovens brasileiros, já experimentam ou experimentaram álcool, tornando-se prejudicial para saúde.

Uma análise mais acurada das respostas dos alunos permitiu inferir como foi a reação dos pais quando souberam do envolvimento dos filhos com drogas. Para ambos os pais tiveram uma reação constrangedora, criando uma situação de conflitos, pois muitos dos alunos tiveram seu primeiro contato com álcool, em festas e banhos com amigos.

Ainda sobre este ponto de vista (Paiva; Ronzani, 2009), afirmam que a família é a base de proteção do adolescente, os pais devem ser autoritários, alertar os adolescentes sobre as drogas através de diálogo, pois a boa comunicação e fundamental para que o indivíduo possa ter direito e liberdade de tirar dúvidas com a família.

Scivoletto e Morihisa (2001, p.30) são categóricos quando afirmam que:

Uma questão fundamental na adolescência é a separação e a individualização do adolescente em relação à família. $O$ estresse e a ansiedade advindos dessa fase aumentam a vulnerabilidade dos adolescentes à pressão dos amigos. Se por um lado ganham autonomia em relação a seus pais, por outro lado adquirem uma forte aliança com seus colegas. Nesse movimento, a influência 
do grupo e a "modelagem", isto é, a imitação de determinados comportamentos a partir de um ídolo, que em geral é o líder do grupo, tornamse especialmente importantes (SCIVOLETTO e MORIHISA 2001, P.30).

Consoante com este entendimento a adolescência é a fase de descoberta, é a fase de experimentar aquilo que o mundo oferece, portanto é nesta fase que a família deve se aproximar e procurar métodos para alertar e proteger os filhos sobre o uso das drogas.

Segundo este estudo, através da análise da fala dos alunos verificou-se que para estes as pessoas que usam drogas não são inteligentes, porque a mente fica perturbada não sabem o que estão fazendo, ou seja, perdem a capacidade de entender algo.

Para complementar a nossa análise e segundo Cardoso; Malbergier, (2014) e Bertoni et al. (2009), estes afirmam que o contato com drogas por parte dos adolescentes e constante na sociedade, sendo que este vício está associado com problemas escolares.

O álcool e a maconha são drogas que apresentam vários fatores problemáticos nas escolas, pois está associado a falta de interação nas aulas, não realização de atividades, notas baixas, desânimo, e faltas que leva o aluno ao abandono escolar.

De acordo com os entrevistados apenas $26,6 \%$ dos alunos souberam responder o que são drogas lícitas e ilícitas e complementaram que o crack, cocaína e maconha são as drogas mais usadas pelos adolescentes. Para os entrevistados drogas lícitas são aquelas permitidas e ilícitas são aquelas não são permitidas.

Observa-se que a maioria dos alunos não sabem diferenciar os tipos de drogas, mas sabem quais as drogas mais consumidas pelos adolescentes. Vale ressaltar que eles afirmam que o Crack é pedra, cocaína é pó e maconha é uma erva medicinal que usam inadequadamente, e dentre esses tipos de drogas, a mais comum pelos adolescentes é o Crack, Maconha e Loló (entorpecente preparado clandestinamente baseado em clorofórmio e éter).

Dados do VI Levantamento Nacional sobre o Consumo de Drogas Psicotrópicas, apontam que álcool e o tabaco são os de maior prevalência de uso na vida, e em seguida os inalantes. No comparativo internacional, o Brasil apresenta índices baixos de consumo de tabaco, crack e maconha, porém o país é um dos maiores consumidores de inalantes (CEBRID 2010). 
Ainda na análise das respostas dos entrevistados, $20 \%$ responderam que usam bebidas alcoólicas frequentemente, para muitos o uso de drogas incomoda pessoas que estão ao redor. Para outros alunos, o uso de drogas proporciona prazer porque deixa a pessoa sem controle da situação. Para alguns alunos o uso de drogas causa alívio para o corpo e a mente.

Neste caso muitos são influenciados por grupo de amigos e perdem a confiança dos pais. De acordo com as respostas dos alunos sobre as consequências que as drogas trazem, muitos responderam que a agressividade com os pais é o tipo de consequência mais vista por eles, no meio em que vivem.

Conforme Caldeira (1999) as primeiras contestações, geralmente, ocorrem no ambiente familiar, onde o adolescente começa a questionar comportamentos que lhes são impostos como se fossem leis e passa a exigir da família e do ambiente que a cerca respostas coerentes aos seus questionamentos. Isso significa a entrada do indivíduo numa nova realidade, com a qual ele vai se relacionar de forma particular e que lhe permitirá reconhecer-se enquanto sujeito. $\mathrm{Na}$ busca de sua identidade passam a ter ideias e ideais próprios, deixando de se espelhar apenas nos pais para se deixar influenciar também pelo grupo de amigos. CALDEIRA (1999, p.16)

Uma análise concludente das respostas dos alunos registradas nos questionários aplicados, revelaram que muitos deles entendem que o trabalho da escola na prevenção de drogas é realizar projetos, palestras que possibilitem aos alunos a participarem e ao mesmo tempo ter meios que sirvam de alerta para orientar os alunos a conversar com os pais e não deixarem ser corrompidos por más influencias existentes na sociedade.

\section{Conclusões}

A análise dos resultados obtidos permitiu identificar se os alunos, tiveram contato com drogas, tanto lícitas como ilícitas, qual o tipo de contato, se alguém da família usa ou usou, quais as consequências do uso, quais as drogas conhecidas por eles. A pesquisa permitiu confirmar que todos os alunos conhecem ou tiveram algum tipo de contato com drogas; todos eles entendem que o trabalho da escola na prevenção de drogas é realizar projetos, palestras que possibilitem aos alunos a participarem e ao mesmo tempo ter meios que sirvam de alerta para orientar os alunos a conversar com os pais e não deixarem ser corrompidos por más influências existentes na sociedade. 


\section{Referências}

ARALDI, J. C.; NJAINE, K.; OLIVEIRA, M. C. GHIZONI, A. C. Representações sociais de professores sobre o uso abusivo de álcool e outras drogas na adolescência: repercussões nas ações de prevenção na escola. Revista Interface (Botucatu) vol.16, n.40, pp. 135-148, 2012.

BERTONI, NEILANE et al. Uso de álcool e drogas e sua influência sobre as práticas sexuais de adolescentes de Minas Gerais, Brasil. Cad. Saúde Pública, Rio de Janeiro, v. 25, n. 06, p. 1350-1360, jun. 2009.

BRASIL. Ministério da Educação. Parâmetros Curriculares Nacionais: terceiro e quarto ciclos: apresentação dos temas transversais. Secretaria de Educação Fundamental - Brasília: MEC/SEF; 2001

BRASIL. Secretaria de Educação Fundamental. Parâmetros curriculares Nacionais: Ciências Naturais. Secretaria de Educação Fundamental. Brasília, MEC, 1998.

BOENTE, Alfredo; BRAGA, Gláucia. Metodologia científica contemporânea para universitários e pesquisadores. Rio de Janeiro: Brasport, p. 79-98, 2004.

BUCHER, R. Visão histórica e antropológica das drogas. In: FIGUEREDO, R. (Org.). Prevenção ao abuso de drogas em ações de saúde e educação: Uma abordagem sociohistórica e de redução de danos. NEPAIDS, 2002.

CALDEIRA, Zélia Freire. Drogas, indivíduo e família: um estudo de relações singulares. [Mestrado] Fundação Oswaldo Cruz, Escola Nacional de Saúde Pública; 1999.

CARDOSO, LUCIANA ROBERTA DONOLA; MALBERGIER, André. Problemas escolares e o consumo de álcool e outras drogas entre adolescentes. Psicol. Esc. Educ., Maringá, v. 18, n. 01, p. 27-34, jun. 2014.

CARDOSO, V., DE SOUZA, R. D., DE CASTRO, E. B., MUELLER, E. R., \& MELLO, G. J. Lícitas e ilícitas: as drogas como temática no ensino de Ciências. Revista Monografias Ambientais, 14, 10-22. (2015).

CENTRO BRASILEIRO DE INFORMAÇÃO SOBRE DROGAS PSICOTRÓPICAS (CEBRID). II Levantamento domiciliar sobre o uso de drogas psicotrópicas no Brasil: estudo envolvendo as 108 maiores cidades do país- 2005.

CEBRID - CENTRO BRASILEIRO DE INFORMAÇÕES SOBRE DROGAS PSICOTRÓPICAS, VI Levantamento Nacional sobre o Consumo de Drogas Psicotrópicas entre Estudantes do Ensino Fundamental e Médio das Redes Pública e Privada de Ensino nas 27 Capitais Brasileiras - Universidade Federal de São Paulo - UNIFESP, 2010.

CFP - Conselho Federal de Psicologia. Drogas, Direitos Humanos e Laço Social. Brasília: CFP, 2013. 160p.

LIMA, E. H. Educação em Saúde e Uso de Drogas: Um Estudo Acerca da Representação das Drogas para Jovens em Cumprimento de Medidas Educativas. Tese (Doutorado). Programa de Pós-Graduação em Ciências da Saúde do Centro de Pesquisas René Rachou. XVII, 229 f. Belo Horizonte, 2013. 
MARTINS, Mayra Costa; PILLON, Sandra Cristina. A relação entre a iniciação do uso de drogas e o primeiro ato infracional entre os adolescentes em conflito com a lei. Cad. Saúde Pública, Rio de Janeiro, v. 24, n. 05, maio. 2008.

MELLO, G. J. Ensino de Física na Amazônia Legal: Experiência na Escola do Campo. São Paulo-SP: Editora Baraúna SE Ltda., 2011. 122p.

MELLO, G. J., SANTOS, V. M. P., PAZ, R. C. R. Física Ambiental e Educação do Campo: Experiência em Ensino Significativo na Amazônia Legal. Revista Pedagogia em Foco, v.7, p.126 - 144, 2012.

OMS (Organização Mundial da Saúde). Reagindo aos problemas das drogas e do álcool na comunidade. São Paulo: Livraria Santos Editora, 1992.

PAIVA, Fernando Santana de; RONZANI, Telmo Mota. Estilos parentais e consumo de drogas entre adolescentes: revisão sistemática. Psicol. estud., Maringá , v. 14, n. 01, p. 177 183, mar. 2009.

PASUCH, CLAMARTA; DA SILVA OLIVEIRA, MARGARETH. Levantamento sobre o uso de drogas por estudantes do ensino médio: Uma revisão sistemática/Survey on drug use among high school students: A systematic review. Cadernos Brasileiros de Terapia Ocupacional, v. 22, n. 1SE, 2014.

ROZIN, Leandro; ZAGONEL, Ivete Palmira Sanson. Fatores de risco para dependência de álcool em adolescentes. Acta paul. enferm., São Paulo , v. 25, n. 02, p. 314-318, out. 2012.

SANCEVERINO, S. L.; ABREU, J. L. C. Aspectos epidemiológicos do uso de drogas entre estudantes do ensino médio no município de Palhoça, 2003. Ciência \& Saúde Coletiva, Rio de Janeiro, v. 9, n. 4, p. 1047- 1056, 2004.

SANTOS F.I.O. O Saber Local E A Sua Expressão Emtecnologias Sociais No Município De Codó, Estado Do Maranhão. - (Dissertaçãode Mestrado). 2013.

SCIVOLETTO, S. Tratamento psiquiátrico de adolescentes usuários de drogas. In: FOCCHI, G. R. A et al. Dependência química: novos modelos de tratamento. São Paulo: Roca, 2001.

SCIVOLETTO, S.; MORIHISA, R. Conceitos básicos em dependência de álcool e outras drogas na adolescência. Jornal Brasileiro de Dependência Química, 2, 30-33, 2001.

SOLDERA, M., DALGALARRONDO, P., CORREAA FILHO, H. R., \& SILVA, C. A. (2004). Uso de drogas psicotrópicas por estudantes: prevalência e fatores sociais associados. Revista de Saúde Pública, 38, 277-283.

Vieira, D. L., Ribeiro, M., Romano, M., \& Laranjeira, R. R. (2007). Álcool e adolescentes: estudo para implementar políticas municipais. Revista de Saúde Pública, 41, 396-403. 